\title{
Emission properties of dental materials and hard dental tissues
}

\author{
by M. Dabrowski, R. Dulski, S. Zmuda*, P. Zaborowski*
}

Institute of Optoelectronics, Military University of Technology,

2 Kaliskiego Str., 00-908 Warsaw, Poland, e-mail: mirdab@wat.waw.pl

* Dentistry Institute, Central Clinical Hospital of Military Medical Academy,

78 Koszykowa St. 00-909 Warsaw

\begin{abstract}
This paper is dedicated to the calculations of the emissivity coefficient of selected dental materials and hard dental tissues, which has decisive meaning to the real temperature measurements using the radiometric equipment e.g. thermovision cameras.
\end{abstract}

\section{Introduction}

The knowledge of temperature values in dentistry is important because of the fact that the temperature changes arise while dental procedures stimulate odontoblasts to produce secondary dentin or cause reverse changes in pulp itself if the amount of the heat penetrating to dental tissues causes the pulp temperature increase in a few degrees. It is known [1-4] that the temperature increase inside the pulp of $5.5^{\circ} \mathrm{C}$ of Rhesus Macaca monkeys had causes vitality less of $15 \%$ of teeth, which were examined.

The researches leaded till now by the authors using the thermovision camera allowed to evaluate the temperature difference between the examined areas of the same dental material or the same tissue of the tooth. In the examination of thermal injury of dental equipment in the clinical circumstances we are interested in the real temperature value, which cannot be measured using radiometric equipment without knowledge of the emission properties of the observed materials and tissues.

This fact appears well in Fig. 1 where the apparent temperature distribution of four different dental materials placed on the homogeneous background in a thermostat is shown.

\section{Method of emissivity coefficient calculation}

The calculations of the emissivity coefficient were performed using reflection method [5] in the spectral range of $8-12 \mu \mathrm{m}$. The reflection coefficient measurements were made using FT-IR 1725X spectrometer (Perkin Elmer) shown in Fig. 2.

\section{Results of emissivity coefficient calculations}

For the examination the enamel and the most popular materials for filling cavities were used: Tetric Ceram, Valux Plus and Compoglass F. Fig. 3-7 show results of the spectral emissivity coefficient calculations for this materials. 
The chart in Fig. 8 shows average values of emissivity coefficients of tested dental materials in the spectral band of $8-12 \mu \mathrm{m}$.

\section{Conclusions}

Our examinations point out the emissivity coefficient difference of the dental materials chosen for our researches. If the differences in the emission properties of the materials are not included, it leads to the errors in the real temperature definition of a few degrees. The examination shows that the emissivity coefficient value depends not only on the kind of the material but also on its color. That's why it is important to define and catalogue the emissivity coefficient of both dental materials used for the cavity fillings and hard dental tissues including their typical colors.

\section{REFERENCES}

[1]. Zach L, Cohen G., Thermogenesis in operative techniques, comparisons of four methods, J Prosthet Dent 1962; 12:977-84.

[2]. Noyborg H, Brannstrom J., Pulp reaction to heat, J Prosthet Dent 1968; 19:605-12.

[3]. Carson J, Rider T, Nash D., A thermographic study of heat distribution during ultra-speed cavity preparation, J Dent Res 1979; 48:1681-4.

[4]. Bhaskar SN, Lily GE. Intrapulpal temperature during cavity preparation, J Dent Res 1965; 44:644-7.

[5]. Ascetta J.S., Shumaker D.L., eds, The Infrared and Electro-Optical Systems Handbook, SPIE Optical Engineering Press, Bellingham (1993).

[6]. IR Imaging Radiometer - Operator's manual, Inframetrics Inc. 1992.

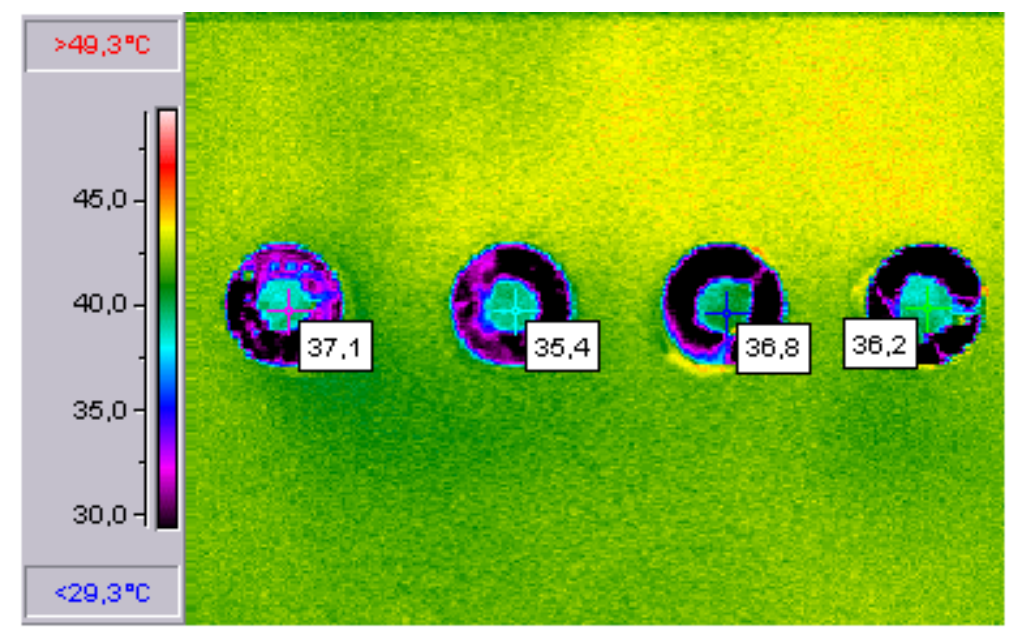

Fig. 1. Apparent temperature distribution of dental materials. 


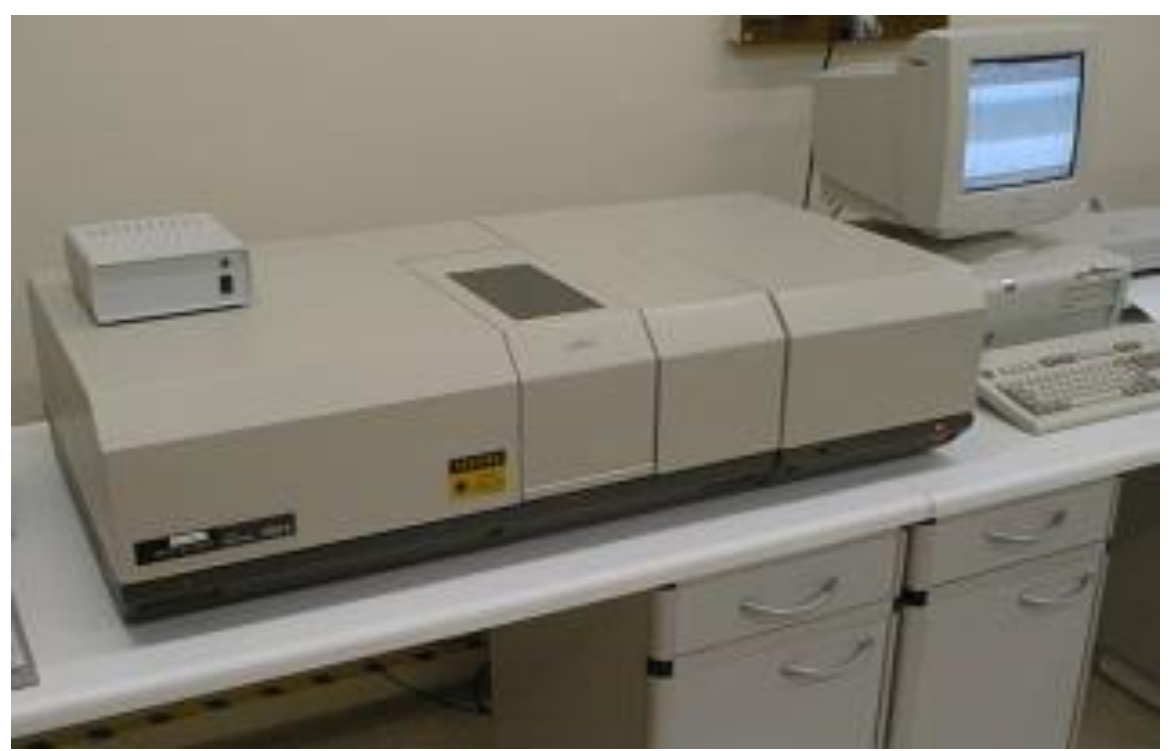

Fig. 2. Laboratory set-up for reflection coefficient measurement.

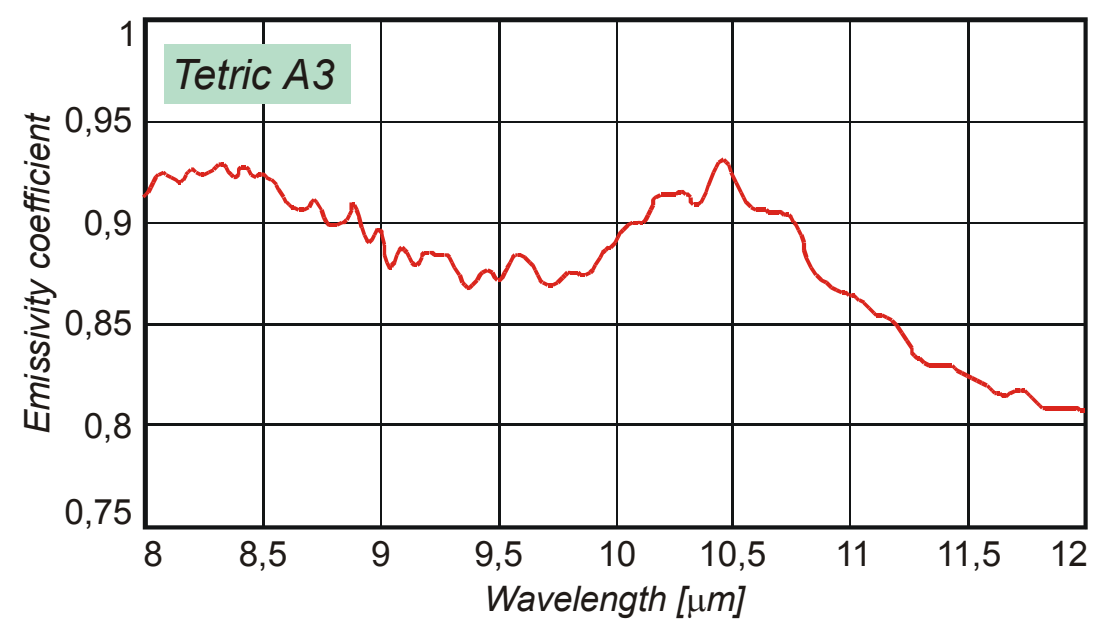

Fig. 3. Emissivity coefficient of Tetric A3 in 8-12 $\mu \mathrm{m}$ spectral band.

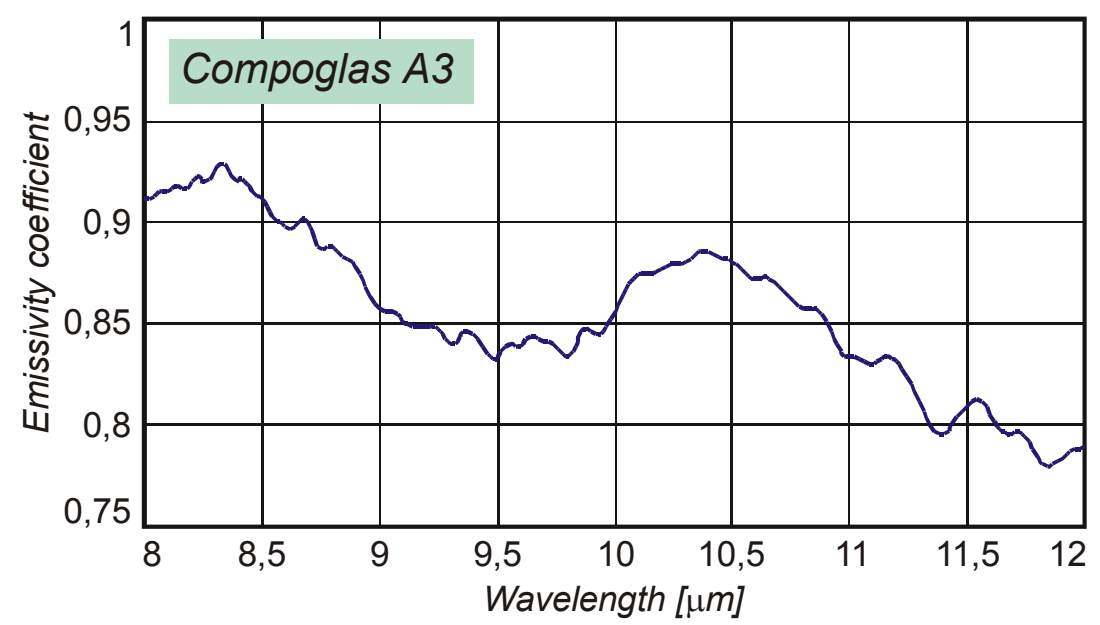

Fig. 4. Emissivity coefficient of Compoglas A3 in 8-12 $\mu \mathrm{m}$ spectral band. 


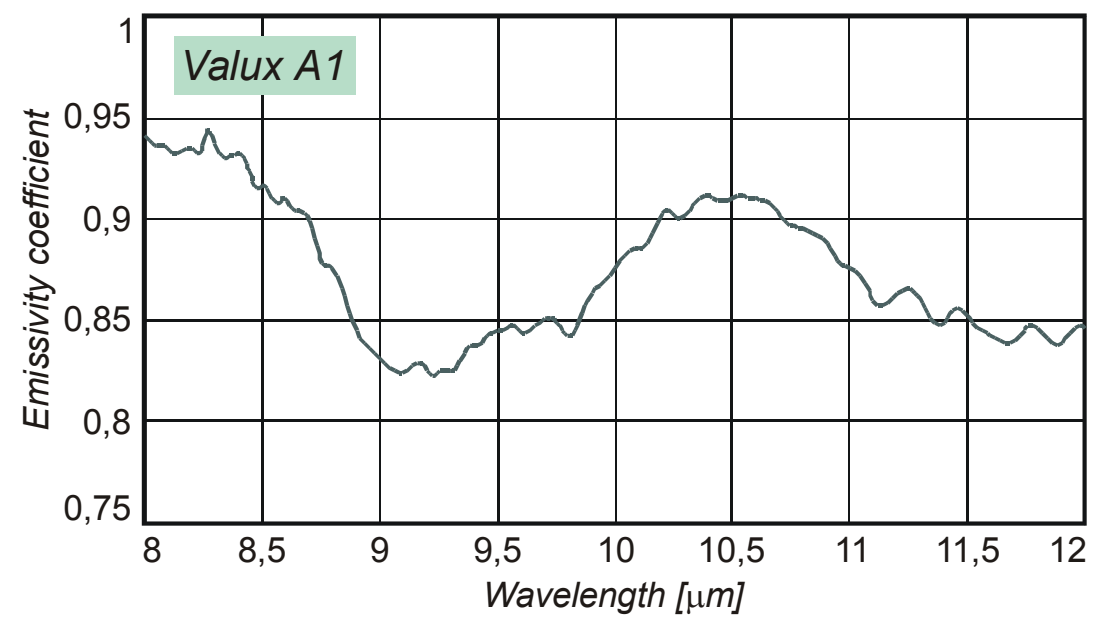

Fig. 5. Emissivity coefficient of Valux A1 in 8-12 $\mu \mathrm{m}$ spectral band.

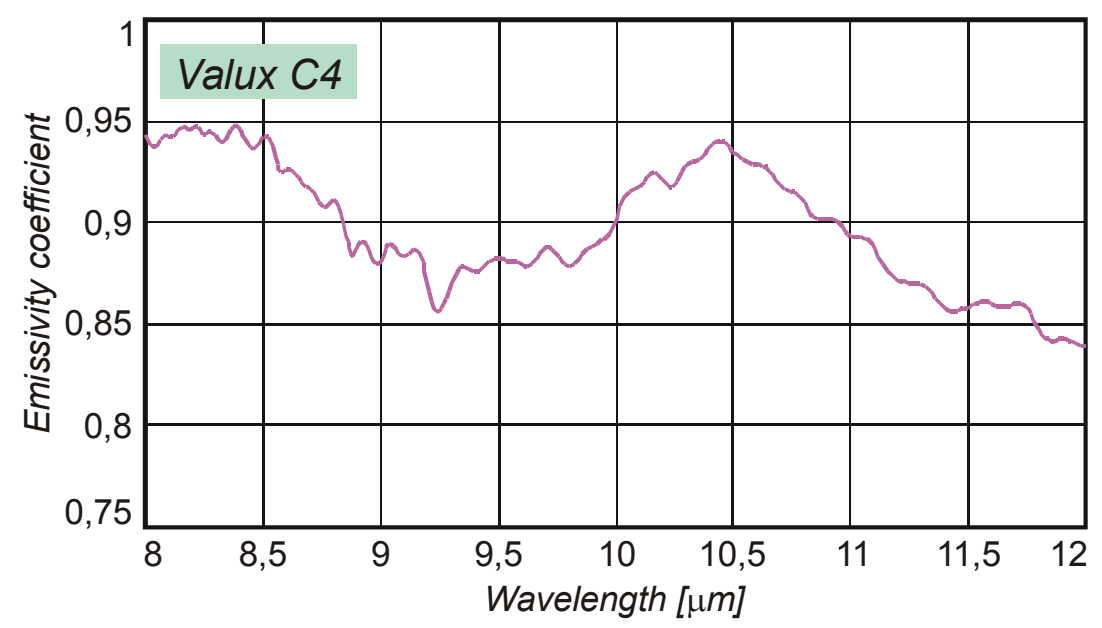

Fig. 6. Emissivity coefficient of Valux C4 in 8-12 $\mu \mathrm{m}$ spectral band.

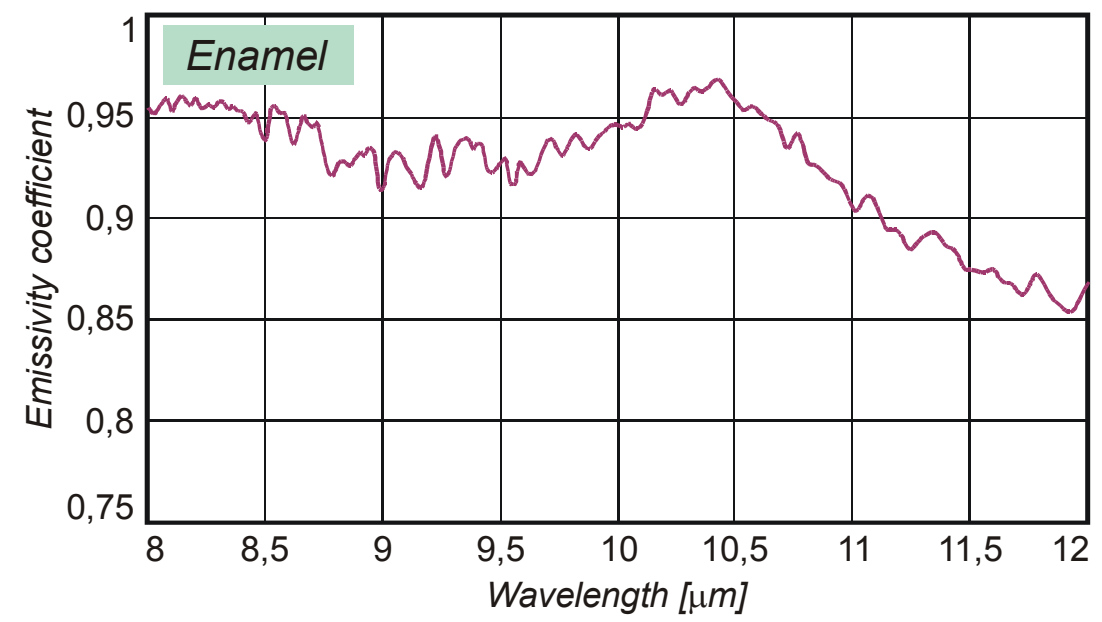

Fig. 7. Emissivity coefficient of the enamel in 8-12 $\mu \mathrm{m}$ spectral band. 
http://dx.doi.org/10.21611/qirt.2000.003

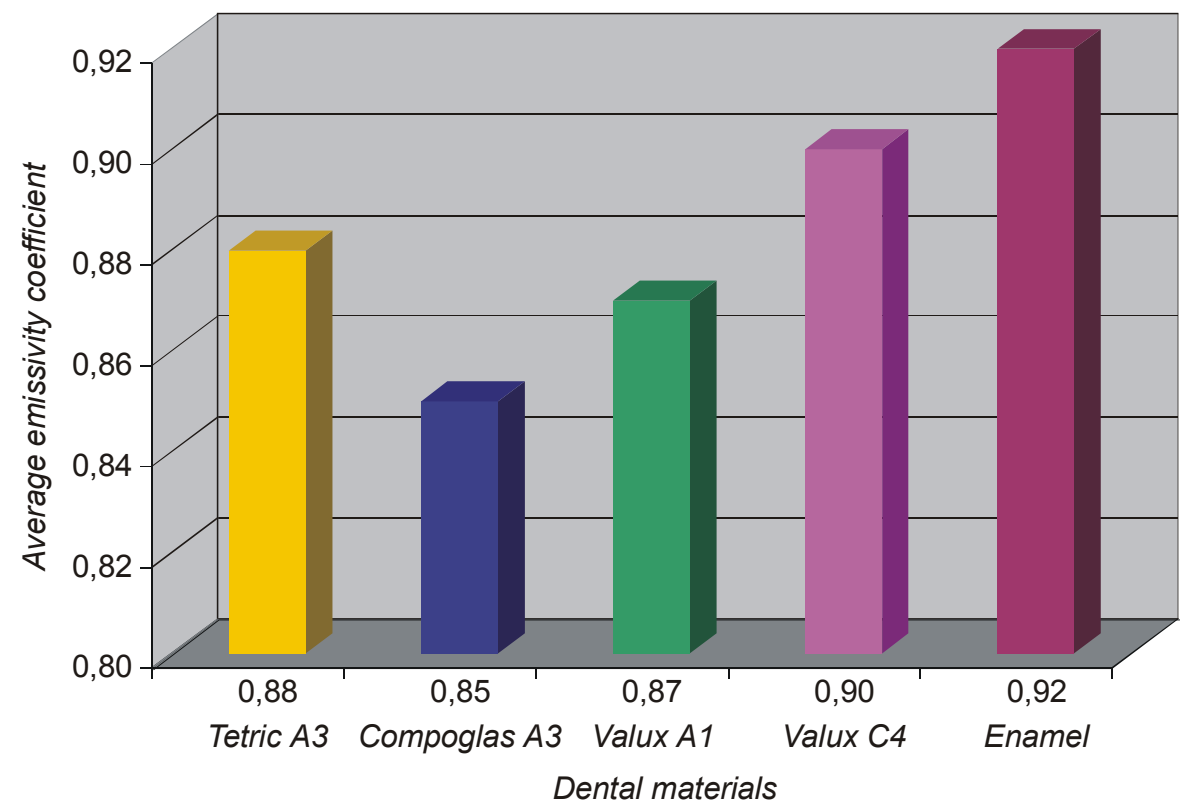

Fig. 8. Average emissivity coefficient of dental materials and the enamel in the spectral band of 8-12 $\mu \mathrm{m}$. 